\title{
OPEN
}

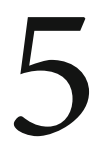

Price and Value of Audiovisual Products

\begin{abstract}
When an audiovisual product is being traded, the costs and revenues related to it are not sufficient to express its value; on the contrary, it is necessary to analyse the dynamics of pricing. Price can be considered a synthetic indicator of the exchange value. However, price is influenced by variables related to the functioning and structure of the market itself. Therefore, while the analysis of costs and revenues represent the basis for the pricing of audiovisual products, it must also be accompanied by the study of two more variables, namely: demand and competition.

The chapter proposes a theory of pricing and value related to audiovisual products based on classic literature on pricing, suitably contextualised to the audiovisual industry.
\end{abstract}

La Torre, Mario. The Economics of the Audiovisual Industry: Financing TV, Film and Web. Basingstoke: Palgrave Macmillan, 2014. DOI: 10.1057/9781137378477.0010. 


\subsection{Introduction}

When an audiovisual product is being traded, the costs and revenues related to it are not sufficient to express its value; on the contrary it is necessary to analyse the dynamics of pricing. Price can be considered a synthetic indicator of the exchange value. However, since it is functional to the sale of the product on the market, price is influenced by variables related to the functioning and structure of the market itself. Therefore, while the analysis of costs and revenues represents the basis for the pricing of audiovisual products, it must also be accompanied by the study of two more variables, namely: demand and competition.

This chapter proposes a theory of pricing and value related to audiovisual products based on classic literature on pricing, suitably contextualized to the audiovisual industry. The theoretical model is a useful tool for audiovisual companies, financial intermediaries and potential funders of production processes.

\subsection{A theoretical framework for pricing}

The study of price matches with the analysis of pricing policies which, in turn, define strategies and pricing models related to specific determinants, as well as the price level and structure (Figure 5.1).

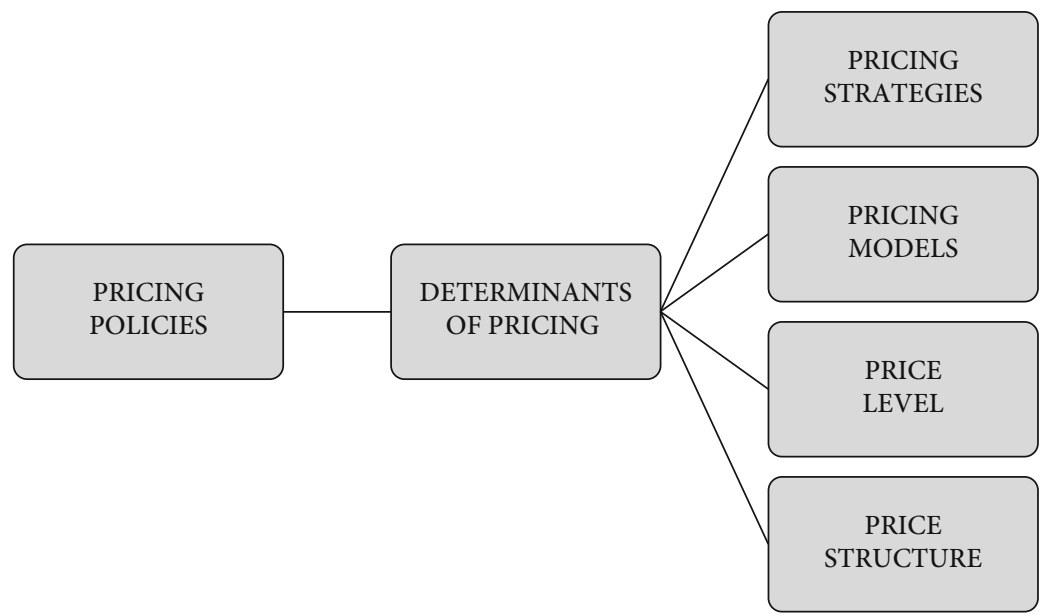

FIGURE 5.1 Pricing policies 
In general terms, pricing policies should be understood as the totality of decisions contributing to price setting of a product or service sold to the final consumer. These decisions depend on several determinants. It is not only the industrial cost of a given good or service to determine its final price. Modern pricing policies embrace, in addition to economic variables, a number of other factors, internal and external to the firm producing the good, and it often leads to setting a price that is dissociated from the production cost.

Pricing determinants may be divided in three major categories (Figure 5.2):

a) economics of a company - costs, risks and revenues;

b) market demand for that particular product;

c) competition - the number and behaviour of the competitors.

Narrowing pricing evaluation to the accounting items and the relationship between costs and revenues would simply confine the price analysis to a single dimension among the many adopted by modern pricing policies. In regards to modern enterprises, it is the combination of multiple factors that explains the pricing strategies and models, as well as the price level and structure, thus defining different typologies of price.

It is possible to affirm that, often, companies decide on prices which do not consider costs and potential revenues, even though the prices may still be consistent with the company's business strategies and

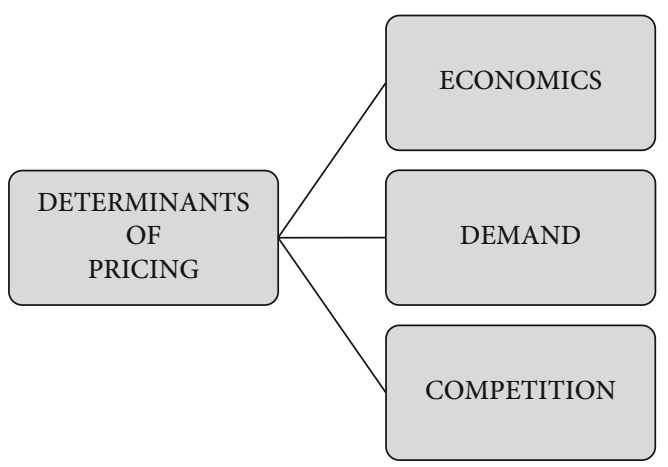

FIGURE 5.2 Determinants of pricing 
market dynamics. In brief, there are pricing policies dissociated from the economics of the product that:

a) determine profits, because they enable high sales volumes;

b) cause a negative balance between the product's costs and revenues, and still contribute to increasing the company's profits as they help to sell other products;

c) allow the achievement of strategic objectives, while causing a negative impact on balance sheet in the short term - as happens in the case of low price aimed at attacking a new market.

\subsection{The economics of pricing}

From purely economic and accounting point of view, the price of an audiovisual product should allow for the costs - both financial and operational and the production risks, to be covered by the revenues deriving from selling a given quantity of the product and still generate a profit (Figure 5.3).

In analytical terms, it can be expressed as:

$$
\text { price } x \text { quantity }=\text { costs }+ \text { risks }+ \text { mark-up }
$$

and:

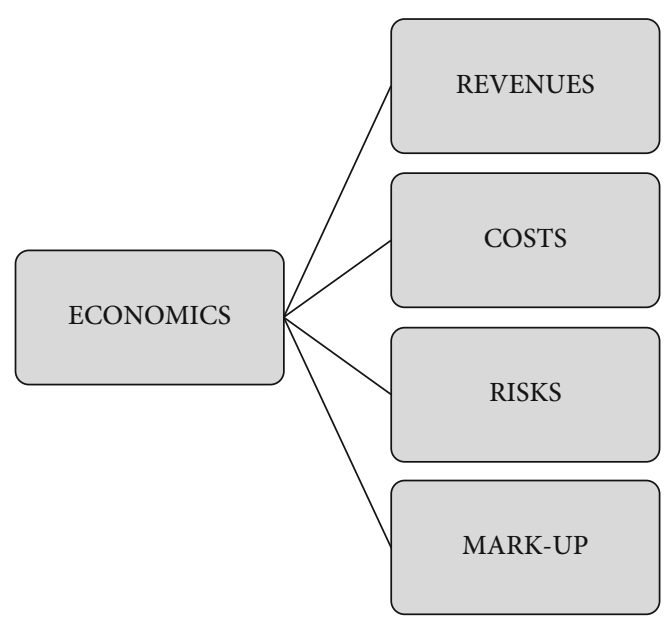

FIGURE 5.3 The economics of pricing 
the Formula 5.1 can also be expressed as:

$$
\text { revenues }=\text { costs }+ \text { risks }+ \text { mark-up }
$$

or as:

$$
\begin{aligned}
\text { sales revenues }= & \text { operational costs }+ \text { financial costs } \\
& + \text { risks costs }+ \text { mark }-u p
\end{aligned}
$$

\section{Price and costs}

When defining a pricing policy it is important to take into consideration the cost of the product in the first place. Such an approach allows establishing what is called the "internal price" or the price calculated on the basis of the costs incurred by the producer without considering any market variable. According to this approach there are two types of internal prices:

\section{- floor price:}

the floor price is the price that corresponds to the amount covering the direct costs;

- break-even price:

the break-even price refers to the price that allows the company to recover total (direct and indirect) costs of a product. In this kind of estimation it is necessary to take into account the production volume in relation to what the overhead costs can be allocated. Since the break-even price depends on the product quantity, it is convenient for the producer to assume a range of values, from a minimum to a maximum break-even price, in relation to different estimated production volumes. In the case of audiovisual companies, the volume of production takes on a different connotation than that of other companies. Audiovisual companies produce prototype goods, one different from another, and therefore, the production volume coincides with the number of products, one different from another, realized in a year; moreover, instead of considering the number of units sold for each product, audiovisual firms take into account the number of right exploitations for any single product.

And therefore the major concern of an audiovisual company is to identify the price level that would cover both the direct costs and indirect costs attributable to that product. The greatest difficulty at this stage is that of an exact and precise estimation of costs. 
In this context, the production model chosen by a company and its size result in a different methodology and accuracy in estimating costs. In-house productions determine greater complexity of the allocation of indirect costs to a single product. The complexity increases proportionally to the complexity of the company itself. Most film production companies, for example, are small in size and often produce only one film a year. In such cases, the allocation of overhead costs does not pose particular problems. In the case of television companies, on the contrary, the structure's complexity and the large quantity of produced programmes make it more complex allocating overhead costs among different products. In the case of commissioned productions, a company delegates the production to a third party-producer. The direct costs agreed between the commissioning company and the executive producer are estimated accurately, item by item, while overhead costs faced by the executive producer are generally referred to as a lump sum.

\section{Price and revenues}

From an economic and accounting point of view, costs are offset by revenues. The difficulty of estimating the revenues from audiovisual products ex ante is caused by the unpredictability of the market response to the products and whether they will by appreciated by the audience. Therefore, it becomes complicated to estimate precisely the level of revenues and to foresee whether they will be sufficient at least to cover the costs. The economic literature defines the audiovisual product as an experience good - that is a good that finds its value/success in the experience of enjoyment of the consumer. This experience is unique and can be different also in respect to these products that have already been "tested" on the market - which is the case of remakes, sequels or of works inspired by previous productions that enjoyed a great success with the audience. Repeating a success can never be taken for granted.

There are examples in the American and Anglo-Saxon scientific literature of undertakings aimed at identifying quantitative methods useful to estimate the prospective revenues of a film. However, tests carried out on the proposed models did not lead to meaningful results, and the identification of a reliable model for forecasting film revenues to this day remains a challenge ${ }^{1}$.

In order to manage the uncertainty of the revenue forecast, audiovisual companies fix a prudential revenue goal, that is, a rate of return large 
enough to compensate a possible negative variance between estimated and actual revenues. Economic determinants of pricing make audiovisual companies strongly profit-oriented; that leads to a tendency to add mark-up resulting in high final prices. High mark-up observed in the audiovisual industry is caused by the difficulty in estimating revenues.

Such an approach leads to defining a new category of internal price, the target price:

- target price:

the target price corresponds to the price level which, in addition to covering direct and indirect costs, allows a company to achieve a desired profit. It is influenced by the assumed production volume. The profit margin can be expressed in relation to a particular return rate of the invested capital or, more simply, as a fixed margin to be added to the break-even price (mark-up).

Therefore, from an economic and accounting point of view, price can be expressed as (Formula 5.4 and Figure 5.4):

$$
\text { target price }=\text { break-even price }+ \text { mark-up }
$$

In the case of in-house productions, companies must estimate revenues and fix a profit rate. The market itself will then confirm or deny the accuracy of the forecast. If a company decides on commissioning a production, the costs will include the executive producer's fee. For the executive producer determining a price is less complicated. The costs will be agreed with the commissioning company, and revenues are

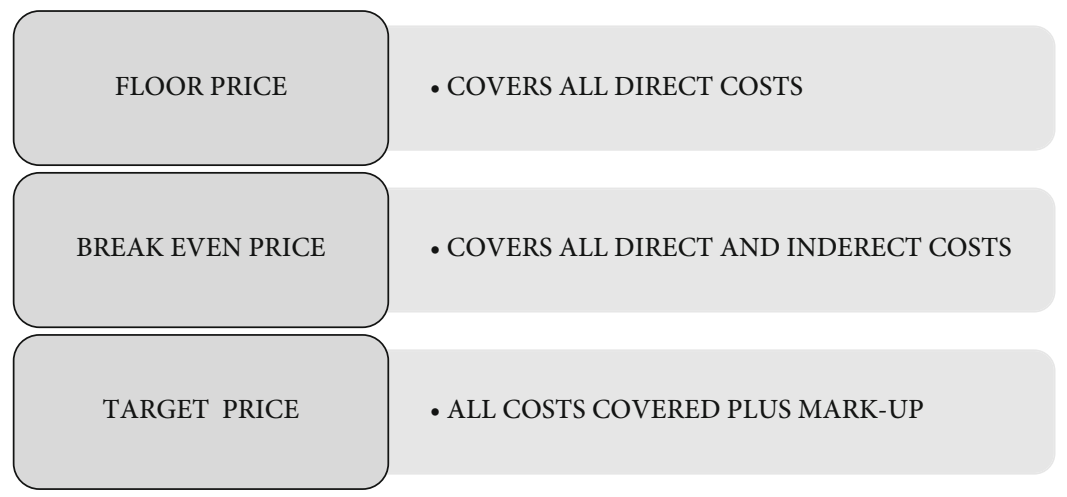

FIGURE 5.4 Different dimensions of price 
reflected by the fee, which is the mark-up. The fee depends, in large part, on the negotiating power of the counterparties. If the fee is too low, the commissioning company risks that the executive producer will be forced to reduce production costs, with potential harm to the quality of the final product. An excessively low fee, which is not consistent with the break-even price or the target price, puts the production at risk, creates a moral hazard on the part of the executive producer and may affect the quality of the product. In contrast, when the fee is too high, in addition to mark-up, it can also include a part of the overhead costs incurred by the executive producer, and the moral hazard of the executive producer occurs when the overhead costs include also those costs which are not directly attributable to the production.

\section{Revenues, price and value of audiovisual products}

The price of an audiovisual product can be considered an indicator of the value of the product itself. As the price incorporates the prospective revenue and desired profit, it is possible to say that the value of an audiovisual product is strongly dependent on revenue prospects on various exploitation markets.

As already explained, not all audiovisual products are able to access all national markets, and even fewer access foreign markets. Therefore, exploitation rights holders need to assess, on the basis of artistic and commercial features of the product, what are the potential revenues and which market to choose when orientating sales efforts. If it is true that the producer company will have to set a price which allows it to recover costs and make a profit, then it is also true that this price is highly correlated to the estimated potential revenues.

In analytical terms, and with the use of Formulas 5.1, 5.2 and 5.3, it is possible to express the price of an audiovisual work according to Formula 5.5, which expresses the price by discounting the expected revenues from various markets of exploitation:

$$
\begin{aligned}
P= & \text { Rbox office }+ \text { RFree } T V+R P a y T V+R H V+R A \\
& + \text { RNM }+ \text { RFM }
\end{aligned}
$$

where:

$R H V=$ revenues from Home Video

$R A=$ revenues from ancillary rights and derivatives

$R N M=$ revenues from New Media

$R F M=$ revenues from foreign markets. 
The value of an audiovisual product is expressed by the discounted value of future revenues generated by the work on various markets of exploitation. This estimate is crucial to the fixing of the selling price of the product, as well as the price of the licensing of the exploitation rights.

As anticipated, the estimation of revenues of an audiovisual product contains some critical elements:

- it is subject to the audience approval of the product and therefore, attributable to an emotional experience that is difficult to assess ex ante;

- it refers to different channels of exploitation;

- it is differentiated for different territories, based on the forecasts of different responses from the audience;

- for each territory, the estimated revenue of the producer may differ with that of the local counterpart acquiring exploitation rights.

As the estimates of future revenues differ for different exploitation markets and territories, it can be stated that the same audiovisual work will have different prices on different exploitation markets and territories.

The difficulties arising from the forecast of revenues in different territories and in different markets of exploitation have forced professionals to look for empirical solutions inspired by their sense and experience, rather than from scientific models.

In order to deal with the forecasting difficulties, audiovisual companies use specific parameters to estimate the future performance of a product. For films primarily intended for cinema, it is common practice to consider such a parameter the revenues from ticket sales (box office). For television products, primarily or exclusively intended for television, the parameter is the share.

For films, the box office is the variable that mostly affects the sale price of all other rights of exploitation. When the sale is made before the film is released in the cinema, the price is set based on an estimate of the potential box office.

The share expresses the number of viewers counted while a television programme is being broadcasted. As it is calculated during the broadcast, for the purposes of presales, it is also necessary to estimate the share ex ante. The share of a feature film used for television exploitation, after being released in the cinema, is strongly influenced by the box office. There is a positive correlation between the box office and share. Most successful films (in terms of the box office) usually get high share. 
When the exploitation rights refer to foreign territories, estimating revenues is even more complicated, due to the fact that the box office and share recorded on the native market are less meaningful. Different tastes of audiences, from different territories, may contradict the success of a product in its country of origin. When it comes to the sale of rights for foreign territories for example, the established solution is to negotiate all possible exploitation rights; the negotiation of single rights occurs very rarely (i.e., television rights).

As the price is related to potential revenues, the buyer, rather than considering the value in use of the audiovisual work, considers the product as an investment. In this context, the valuation of price is influenced by three factors: (a) the present value of the future revenue at the time of negotiation; (b) the duration of the granted exploitation period; and (c) the frequency of use, referring to the number of opportunities for exploitation in the context of the negotiated period (Figure 5.5).

The price of an audiovisual product depends on the estimated revenues, which are a function of the type of product, the exploitation period and frequency of use. Assuming other conditions being equal, the buyer is willing to pay a

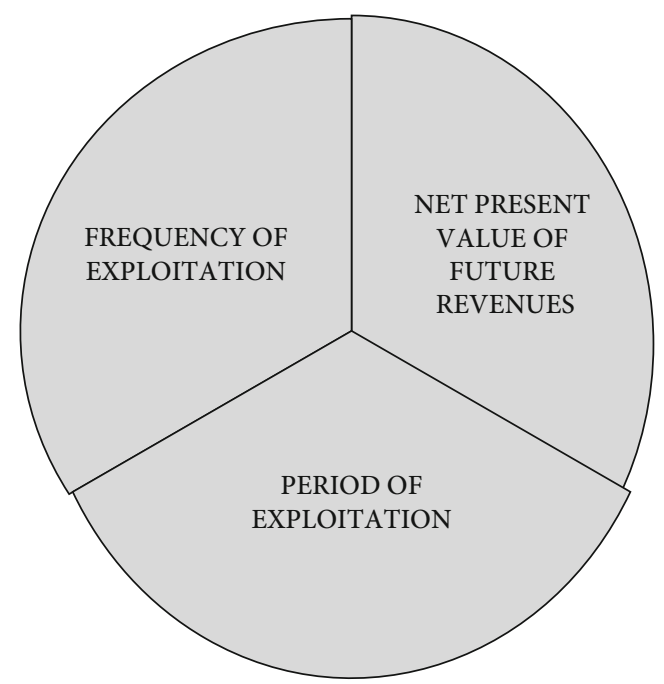

FIGURE 5.5 Value, price and exploitation of audiovisual products 
higher price for the same product if the period of exploitation is longer and the frequency of exploitation higher.

As an example, considering a film released in cinemas, the television rights for a period of five years will be worth less than those granted for 10 years, and the corresponding rights will have different prices. In this context, the maximum price coincides with the purchase of given rights in perpetuity. The extension of the exploitation period increases the volume of potential revenue. The number and opportunities of exploitation negotiated during the purchase of rights also affect the value of a product. This finding is particularly relevant for the television market where, in addition to the exploitation period, negotiations are also associated with the so-called "television runs", or the number of times that a film can be broadcasted. Finally, as the revenues are still only prospective; they must be discounted by a financial process that expresses the value of future revenues at the time of negotiation. Therefore, the choice of discount rate implies an additional choice that affects the price.

In conclusion, the price of an audiovisual product can be expressed as the present value of future revenues referred to individual markets of exploitation ${ }^{2}$. The value is a function of the period of assignment of rights $(t)$ and negotiated television runs $(p)$ :

$$
\begin{aligned}
P(t, p)= & \text { Rbox office }+ \text { RFree } T V+\text { RPay } T V+R H V \\
& +R A+R N M+R F M
\end{aligned}
$$

Formula 5.6 is valid for all television programmes and films, but accessible exploitation markets and ways of exploitations should be evaluated for each product separately. Therefore, the Formula 5.6 will assume different configurations in relation to different products. For example, for products destined for the web, the expression of the price will be:

$$
P \text { web product }(t, p)=R N M
$$

More in general, the increasing co-existence of cross media products and linear and nonlinear media services will lead to a flexible conception of the Formula 5.6, which will be adapted to the specific feature of the product and its release.

As regards to the audiovisual market, the cost of production is scarcely indicative of the value of the products. The value is strongly dependent on potential revenues which, in turn, are a function of the 
distribution costs and, above all, of the response of the public. The positive correlation between production costs and revenue volume is not to be taken for granted and depends strongly on two specific elements, an economic one and a cultural one. In practice, it has been shown that it is not only the production budget that influences the success of a product, but also, and especially, the budget available for the promotion and launch of the product itself. American blockbusters, for example, have budgets to promote and launch almost equal to the cost of production. In Europe, on the contrary, the resources earmarked for the launch of a film are a small part of the industrial cost. In cultural perspective, it should be noted that, in the end, the success of the product is determined by the taste of the public, and the audience response is always uncertain and difficult to predict. It is often uncorrelated to the reputation of the actors and the director, and their previous successes. Several cases of high-budget films, with worldrenowned casts, recording burning commercial disappointments, confirm what is stated above.

The fact that audiovisual products are "prototype" products, that their value depends mainly on the response of the audience, and that this is not predictable, results in the value estimation being a subjective judgment that cannot be verified, until after the airing of the product.

To sum up, the price of an audiovisual product is poorly correlated to the production costs, and it is strongly correlated with the response of the public, the costs of promotion and launch and terms of use of the product itself. Being successful with the public is difficult to predict ex ante. The budget available for the promotion and the launch do not depend on the choices of production companies but are decided by the distribution companies. The ways of exploitation depend on the negotiation of the rights to the product. As a result, the price of audiovisual products: (a) cannot be related to objective parameters and (b) is a prototype price, or hardly comparable with the prices of other products, including those of similar technical and production features.

\section{Not only economics}

Pricing based on costs and revenues is only a starting point for determining the price of audiovisual products. Setting the price according solely to the economics may expose the production company to high risk of adopting inadequate pricing solutions. 
Since the break-even price and the target price are dependent on the number of products and on the markets of exploitation to which they have access, the lack of coincidence between what is assumed ex ante and the response of the market would lead to a methodology of "circular pricing" that is difficult to apply. Lower than expected audience response and number of exploitation markets would force the company to increase the price in order to maintain the same level of profit. Similarly, higher market response could result in price reduction. The difficulty of applying a "circular pricing" induces companies to incorporate in their pricing policies the variables referring to the market demand and the market's competitive structure.

\subsection{Demand and pricing}

Modern pricing policies are not oriented only to the internal dynamics of the firm - on the contrary, they take into account the needs of clients. In such perspective, it is relevant to analyse the demand from buyers before determining prices.

The company must identify its own target price that is compatible with the price accepted by the market. Prospective buyers of audiovisual products can be distinguished for product types. For television products, prospective buyers correspond to other broadcasters or distributors on other markets of exploitation, primarily Home Video and foreign markets. For films, the potential buyer is a film distribution company that will place the product on different markets of exploitation. Producers are rarely able to carry out sales on different markets themselves. For web products, placed freely on web platforms, there is no buyer of exploitation rights that remain with the filmmakers, or the sponsors in the case of branded products. And therefore there is no selling price. Platforms act as distributors without paying the purchase price, or acquiring ownership of the products. The following considerations will, therefore, be largely related to television products and films.

To consider the perspective of a potential buyer means to incorporate into the price three variables: elasticity of demand, value and risk perceived by the buyer, and the degree of asymmetric information between the production company and the buyer (Figure 5.6). Within the audiovisual market, these variables take on specific features that can strongly influence the price and the relative value of a product. 


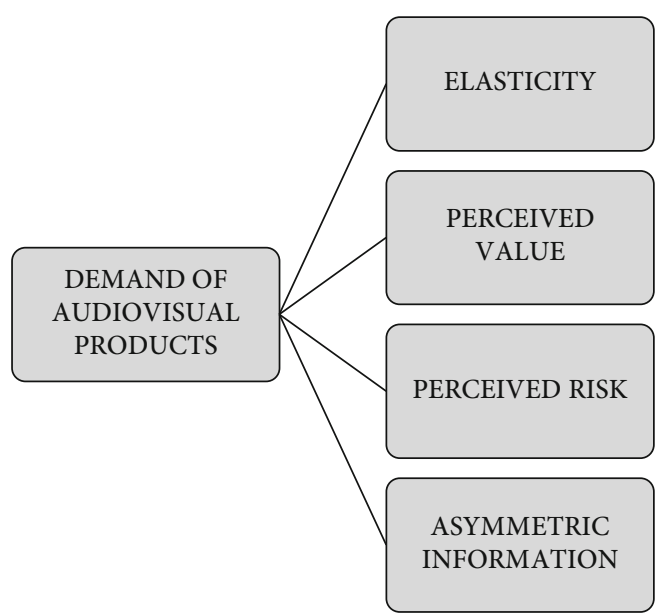

FIGURE 5.6 Demand and pricing of audiovisual products

\section{The elasticity of demand}

The sensitivity of the buyer in relation to the price is defined as "elasticity of demand". In economics, the elasticity is measured as a percentage change in the quantity of product purchased in relation to a percentage change in price of $1 \%$. In conceptual terms, the buyer's reaction to the change in price shows how much the buyer is willing to pay in order to obtain a certain product. It can be affirmed that, the lower the price elasticity of the buyer, the less the buyer is willing to modify its purchase decision if the price increases.

Several econometric studies have highlighted the importance of the price elasticity and have detected the main factors affecting the behaviour of potential buyers of audiovisual products. Using the taxonomy proposed by Nagle and Holden (1994), it is possible to affirm that there are several variables that can explain the low elasticity of demand characterizing the market of audiovisual rights:

1 Distinctive qualities of a product and the absence of substitute goods. Audiovisual products are unique and not replicable. They are prototype goods and experience goods by nature, and therefore are not replaceable. For these reasons, the price sensitivity is generally low, especially among the broadcasters: once a particular product has been identified for a specific need of the programme schedule, 
it is complicated and expensive to find a suitable and comparable substitute.

2 Advantages of a product. The more a product is attractive and able to generate revenues, the lower is the sensitivity to its purchase price.

3 Possibility of a combined investment. This variable is of particular importance in the so-called "packaged sales", in other words, sales of a portfolio of rights relating to a given mix of titles. The basket of rights generally refers to titles of a different nature and appeal. The package includes both top quality titles and those of low appeal. However, the only way to purchase desired titles is to buy them together with those that are not "necessary". This negotiation practice results in a reduced price sensitivity of the buyer towards the less appealing titles.

4 Stock-up effect. The exploitation rights for audiovisual products are granted for a defined period of time, within which the buyer can use them to the extent agreed in the contract. The ability to dilute the exploitation of the purchased rights within the limits of time described in the contract results in a "stock-up effect" that lowers the price elasticity.

Therefore, the lower the demand elasticity in relation to the above-mentioned factors, the easier it will be for the selling company to manage the technical price. The company can more easily reconcile the technical price with profit goal, in the light of a lower sensitivity of the buyer towards the price, and set a higher target price.

Low elasticity of demand helps to dissociate the price of an audiovisual product from economics. The lower it is, the higher is the applicable mark-up applied by the selling firm and, consequently, the greater the distance between target price and technical price.

\section{Price and value perceived by the buyer}

Variables that affect the demand elasticity lead to distinguishing a dimension of price referred to the buyer. More specifically, literature ${ }^{3}$ distinguishes four price dimensions: "monetary price", "non-monetary price", "perceived price" and "perceived value" (Figure 5.7).

The monetary price expresses the financial costs incurred while purchasing the product. The non-monetary price includes also imputed costs of 


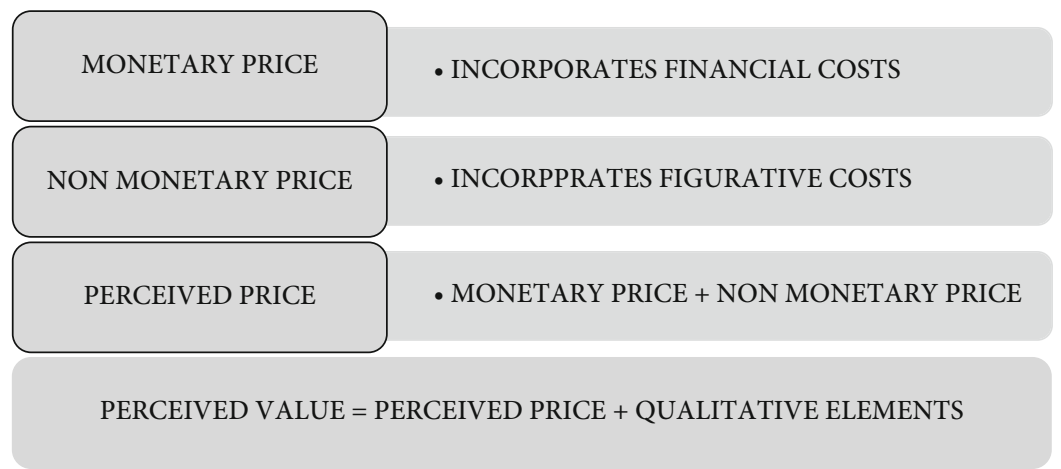

FIGURE 5.7 Different dimensions of price for buyers

time and energy, as well as the psychological costs associated with the purchase. Taken together, monetary and non-monetary price constitute the "perceived price" by the buyer. Therefore, the perceived price may be expressed as: monetary price + non-monetary price. The perceived value expresses the overall assessment that a consumer makes in relation to the usefulness of the product. The assessment considers not only the product - and its intrinsic and extrinsic features - but also different variables that determine its elasticity.

In their pricing policies, therefore, audiovisual companies should consider that, when deciding on a purchase, buyers not only take into account the monetary price, but also, and more likely, the perceived value. It is the perception of the overall value that makes buyers pay certain prices rather than others. If a broadcaster considers a programme crucial to its programme schedule, it will be willing to pay more due to a high perceived value. The concept of perceived value is definitely relevant for the audiovisual market because of the uniqueness of the product negotiated - rights of exploitation - and the nature of a prototype good of audiovisual products.

The perceived value does not coincide with the monetary price and contributes to dissociate the price of a product from economic and accounting variables estimated by the selling company. The target price will deviate from the technical price also because of the value perceived by the customer. The higher the perceived value, the greater the applicable mark-up and, consequently, the distance between target price and technical price. 


\section{Price and risk perceived by the buyer}

The act of buying always involves taking risk by the buyer. In literature, the risk faced by the buyer has been divided into six categories: economic, psychological, performance, physical, social and global ${ }^{4}$.

The economic risk refers to the risk of loss; the higher the purchase price, the higher the loss risk exposure. The psychological risk is due to emotional involvement and possible disillusionment that can come after the purchase. The risk of performance refers to the possibility of not achieving the expected result, considering the price paid for the product. The physical risk is linked to the deterioration of the purchased product. The social risk is due to the social value attributed to the possession of the purchased product. The global risk expresses the synthesis of different types of perceived risk.

Some research ${ }^{5}$ identified the performance risk, the economic risk and the psychological risk as the top three among all the risks perceived by buyers.

As regards the audiovisual market, economic risk and performance risk have an impact on pricing because of the peculiarity of rights of exploitation and because audiovisual products are prototype goods of experiential nature. The performance risk, or the possibility of not getting the expected result from the product, is particularly highlighted.

The lower the perceived risk, the greater the applicable mark-up and, consequently, the distance between target price and technical price.

\section{Price and asymmetric information between buyer and seller}

The difficulty in processing available information and what derives from the lack of information introduce a further influencing factor in pricing, namely the asymmetric information between the parties to the negotiations.

When the buyer is not in a position to evaluate, or obtain, the information necessary for purchase decisions, the price itself becomes an indicative value of quality.

Acquiring and processing available information requires from the buyer a specific know-how and time. Lack of time to acquire and process available information leads to a situation in which the consumer has difficulty in expressing the perceived value and, therefore, considers the price itself to be the indicator of the product value. 
The lack of time and the unavailability of information lead to asymmetric information between buyer and seller. As a result, the price itself becomes an indicator of the product value and helps to distance the target price from the technical price (Wolinsky 1983). The less time available to the buyer, its know-how and available information, the greater the applicable mark-up and, consequently, the distance between target price and technical price.

On the market of television rights, asymmetric information works in more complex manner. It regards two aspects: the quality of the underlying product and the investment value of the product itself. The asymmetric information regarding the product quality is due to the fact that the purchase of rights regards products which have not yet been completed, or that have not been released to the public yet. This kind of asymmetry, for example, is typical of the output contracts and volume deals concluded by broadcasters directly with major film production companies $^{6}$. It is common practice regarding these contracts that a broadcaster undertakes to purchase a package of products which include also the works that are not yet completed, and whose artistic value cannot be assessed yet.

The asymmetric information concerning the investment value refers to the knowledge gap between the parties regarding the revenues deriving from possible exploitations of rights by the buyer. A classic example is that of the purchase of foreign products. Hardly ever the rights owner can assess the potential revenue of the product on the buyer's market with the same accuracy as the buyer itself. In domestic trading, asymmetric information can be related to the existence of pre-agreement for future pre-sale contracts, but not known to the seller.

\section{A multidimensional pricing model for buyers}

The price-quality relationship, from the buyer point of view, leads to a multidimensional model of pricing taking into account different variables crucial to purchase choices. The elasticity of demand, the perceived value and risk, asymmetric information between sellers and buyers, are all elements that play a crucial role when making purchase decisions, and when deciding on the price one is willing to pay (Figure 5.8). Furthermore, the price itself often becomes, for the buyer, the most indicative quality indicator. 


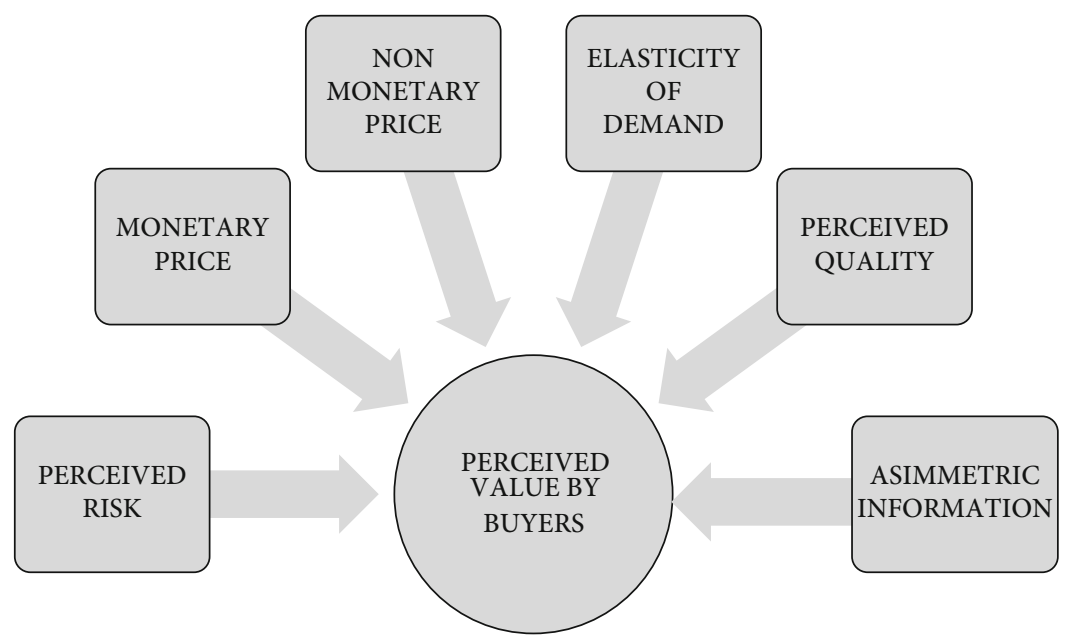

FIGURE 5.8 The determinants of multidimensional price of buyers

The determinants of pricing, related to demand, can create economic space for the target price to distance itself from the technical price, allowing the selling companies to apply mark-up. As a result, the lower is the demand elasticity, the more significant are the perceived value, the asymmetric information and perceived risks - the higher is the final price.

Similarly to what sellers do, buyers also set their own price range within which their purchasing decisions are made, narrowing the economic space for the pricing policies of the sellers. Several studies have shown that buyers are not willing to consider any purchase if the price exceeds the acceptable range. Such a price corridor, determined by the analysed variables, is marked by a minimum price ("buyer floor price") below which the quality perceived by the customer is too low, and by a maximum price ("buyer cap price") congruous with the revenue that can be allocated at the time of purchase. Within this range, it is possible to trace a "reference price" defined as the price on the basis of which the buyer evaluates all other prices (Figure 5.9).

Economic space that the selling company can use for the purposes of setting the price, and its own mark-up, is limited by the price corridor with which the customer defines its reference price. 


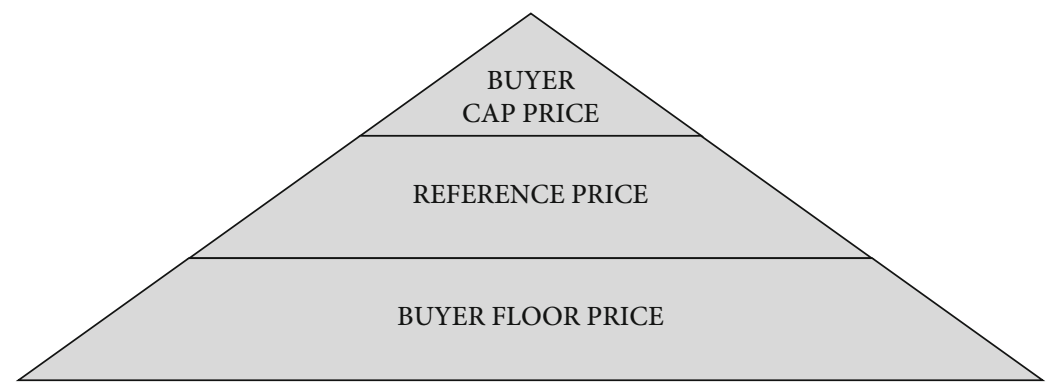

FIGURE 5.9 The price corridor for buyers

It is possible, therefore, to trace the dynamics of the setting of the reference price which develops following several steps: (a) determination of the perceived value, (b) determination of the reference price, (c) determination of the acceptable price range and (d) assessment of the price charged by the seller.

On the basis of the two major theories present in literature (Adaptation Level Theory and Theory Assimilation-Contrast) several studies were conducted ${ }^{7}$ confirming that it is possible to construct the curves of the minimum and the maximum price and, therefore, the acceptable price corridor for a given product.

Therefore, when applying the mark-up and the final price, selling companies must adhere to the buyers' price corridor, if they want to avoid an increase in the price affecting the sale. The lower the price level, the lower the threshold of attention of the buyer; as a consequence the corridor of the buyer's price is less binding. In such conditions, the applicable mark-up, and the final price, can be higher and, consequently, the distance between the target price and the technical price will be larger.

When there is a well-established habit to buy certain goods, the valuation process is combined, and sometimes replaced, by the use of a "usual

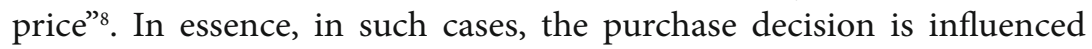
more by a habit to pay a certain price, or at least a price fixed within a certain threshold: the usual price automatically becomes the reference price.

As regards the audiovisual market, the reference price and the usual price assume particular significance especially for the buying broadcasters.

The frequency of purchase affects pricing. In conjunction with repeating purchases, the adoption of the usual price allows the selling companies, in 
the short- to medium-term, to maintain unchanged their mark-up margins and prices applied over time, regardless of the market performance.

\subsection{Competition and pricing}

Pricing policies find in the market structure an exogenous constraint that delimits the seller's pricing policy.

In particular, the intersection between two such variables, as perceived value and structural market conditions, determines four possible situations in which pricing assumes distinct features (Figure 5.10):

a) high perceived value and small number of competitors - this situation is similar to monopoly or differentiated oligopoly, in which the room for pricing policy is big: sellers can take advantage of the high value that the product has in the eyes of the customer, and at the same time do not have to worry about any other competitors.

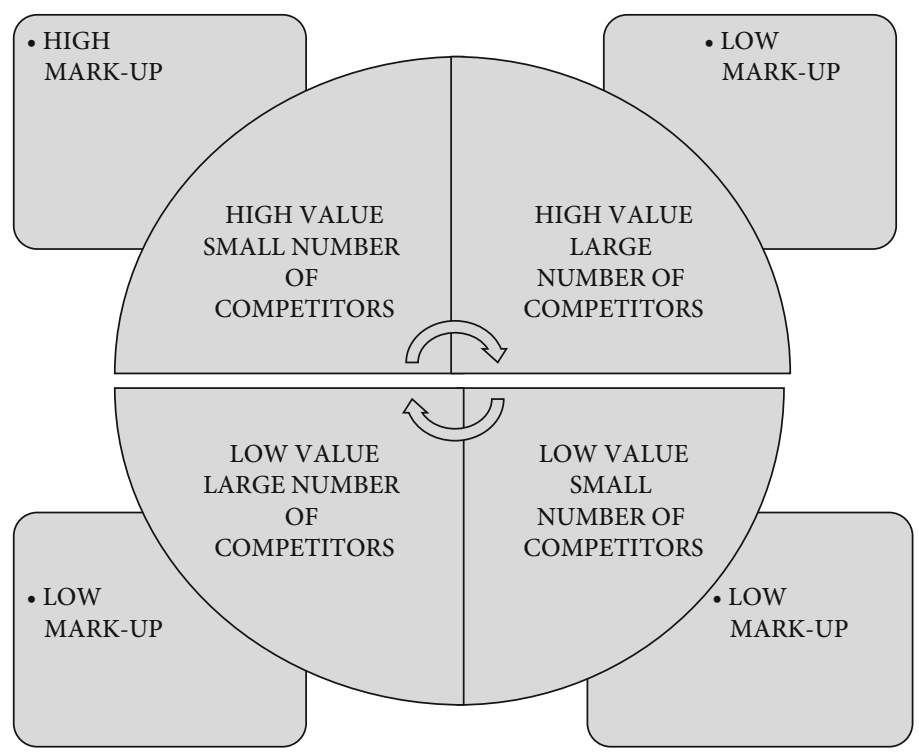

FIGURE 5.10 Perceived value, competition and price Source: adapted from Lambin (200o). 
This situation can be associated with high mark-up and high final prices;

b) low perceived value and large number of competitors - this situation is opposite to the previous one and comparable to pure competition. In this case, the room for pricing policy is restricted, either because the customer does not perceive the product as highly differentiated and irreplaceable, or because of competitors' pricing policy. This situation can be associated with low mark-up and low final prices;

c) low perceived value and small number of competitors - this situation is similar to undifferentiated oligopoly. In this case, the degree of freedom in setting the pricing policy, which comes from a low level of competition, is limited by the low perceived value. This situation can be associated with low mark-up and low final prices;

d) high perceived value and a large number of competitors - this situation is similar to monopolistic competition. Also in this case, the autonomy of pricing exists because of strong product differentiation in the buyer's perception, but it is limited by the high competition. This situation can be associated with reduced mark-up and reduced final prices.

The analysis of the impact of market structure and competition on the pricing policy, however, cannot be reduced only to the assessment of the level of competition. The potential reactions of competitors must also be considered. Regardless of the competition level - high or low - there are favourable conditions for a price reduction and others favourable for a price increase ${ }^{9}$.

For example, in those market situations in which a price change of one company triggers a similar reply of other companies, a price reduction is compatible only if the demand for the product is increasing. If all sellers reduce the price, but the sold quantity remains the same, the profits of all companies decrease. Similarly, the price increase can be prosecuted if the demand increases, or decreases up to the threshold level that leaves the profit unchanged.

In this case as well, four situations can be distinguished:

a) the demand is increasing and the competition reacts quickly;

b) the demand is increasing and the competition does not react; 
c) the demand is not increasing and the competition reacts;

d) the demand is not increasing and the competition does not react.

Different market structures determine different degree of freedom for the company's pricing and have different impacts on the possibility to distance the target price from the technical price.

From an economic point of view, the situation (c) is favourable for neither a reduction nor an increase in price, since it will result in lower profits for the companies. In this case, a change in price could be justified only by other non-economic objectives.

Different reactions of competitors, and different life cycles of the product, result in different degrees of freedom for a company's pricing policy and have different impacts on the possibility to distance the target price from the technical price.

A company which operates on different geographic markets finds itself to be operating within different market structures. And therefore it is possible that, for the same product, one company will have different margins in which to manoeuvre as regards to pricing. Such a condition allows applying different prices for the same product in different areas.

With reference to the European audiovisual industry, it is necessary to distinguish between the competitive structures of the TV market and that of the film market. The first one is generally comparable to a situation of oligopoly, with few large broadcasters that control the market; the latter to a model of pure competition, with many small-size producers. The value perceived by potential buyers changes in relation to the product, while the demand is generally not increasing and undergoes changes in relation to particular products, or in relation to short-term cycles. For this reason, it is not possible to place the audiovisual market in one of the quadrants of Figure 5.10. It is more a matter of situations that vary from sector to sector, and in relation to single products. However, there are some trends that can be identified as characteristic. For television products, a relatively low perceived value of a product on different exploitation markets - primarily Home Video and abroad - is associated to an oligopolistic supply structure. For film products, the supply structure is of competitive type and the perceived value is, on average, relatively low. As a result, with the exceptions of products of particular appeal, the competitive structure of the market contributes to a downward trend in the price. 
Naturally, different territories with different competitive structures, allow for different degrees of freedom for pricing policy and determine different gaps between the target price and the technical price, depending on the geographic market.

Price increases may be motivated by contingent competitive dynamics, as referred to particular markets and particular historical contexts. The development of private national and local broadcasters recorded in Europe since the 1980 os has generated an increased demand on television products and films. Broadcasters not only had to cover the urgent needs of programming, but also chased successful products in order to take market share from their competitors and to consolidate their own position on the market. In those years, therefore, there was a substantial increase in the prices of audiovisual products, both domestic and international - mainly American. This increase was generalized and transferred also on products with relatively low perceived value that could enjoy the "pulling effect" independent of their own characteristics.

\subsection{Structure and level of price}

Structure and level of price are strongly correlated elements. The structure is defined by the quantity and quality elements that make up the price: they define the price level. The price level has different meanings: an internal one, referring to the selling company, and two external ones, referring respectively to demand and competition.

The price structure is defined by the sum of the explicit and implicit components that are incorporated into the final price applied to consumers.

Explicit components are represented by quantitative elements expressed by direct and indirect costs; they determine, namely, the threshold price and the break-even price. Implicit components are due to all those variables that contribute to distance the final price from the breakeven price and to set the target price - including not only the desired profit rate, but also the qualitative components related to demand and competition.

Two algebraic dimensions of price can be distinguished, corresponding to two meanings: the quantitative one and the qualitative one: 
price $=$ amount of money transferred by the purchaser / quantity of goods sold by the seller

price $=$ monetary and non-monetary sacrifices of the buyer / customer's satisfactions

The net effect of the profit rate and quality components lead to a new definition of an "applied target price":

applied target price $=$ break-even price + mark-up

$$
+ \text { qualitative variables }
$$

In this perspective, the selling company can charge a price - the applied target price (or the final price) that can be higher or lower than the target price.

The applied target price may deviate from the target price on the ground that the mark-up not only incorporates the technical profit rate, but also the qualitative elements that can be algebraically added to it to determine positive and negative differences.

Finally, the final price is influenced by the "trigger prices" that configure specific manoeuvre corridors for pricing. These trigger prices relate to the direct cost of the production, the reference price of the buyer and the prices charged by competitors (Figure 5.11).

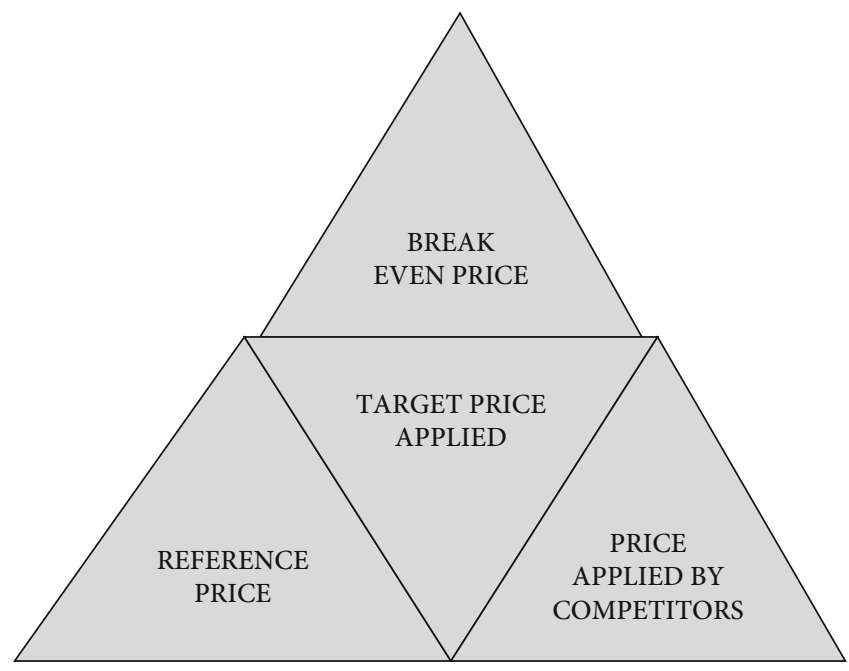

FIGURE 5.11 The corridor of applied target price 
The level of price, therefore, is different for the different dimensions of the price and, with reference to the final price (applied target price), is affected by the complexity of the price structure defined by a variety of quantitative and qualitative components considered by the selling company in accordance with the pricing policy adopted.

On the audiovisual rights market, given the nature of right of exploitation, it is common that the target price is far from the applied target price.

\subsection{Pricing models}

In relation to the above mentioned, it is possible to identify four main pricing models for audiovisual products. Companies may adopt as a reference the individual price of a single product, or the price of a basket of products - these two pricing models are called "product pricing" and "package-based pricing". In this way the pricing model, chosen by the company according to its strategy, defines the priority variable that inspires the price: a single product or a package (Figure 5.12).

On the audiovisual market, usually a combination of product-based models and packaged-based models can be observed. The former are found chiefly on the film market, characterized by small size production

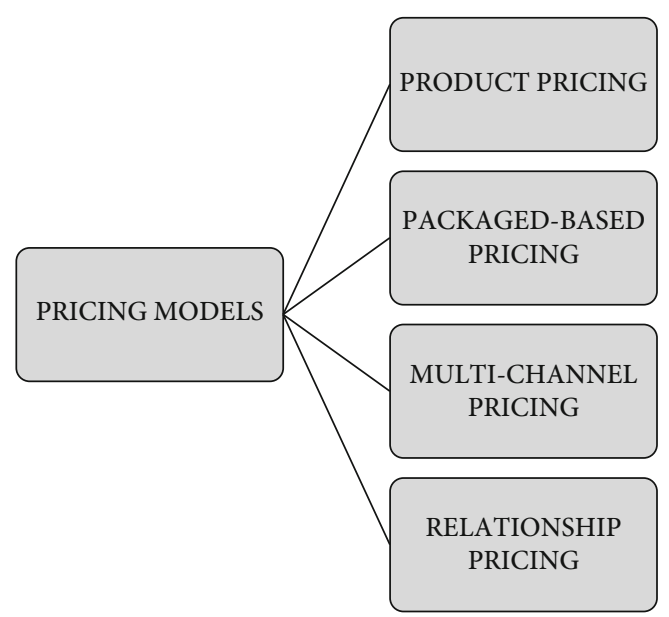

FIGURE 5.12 Pricing models 
companies able to place on the market one product at a time; on the television market, on the contrary, it is common to track prices referred to a portfolio of titles.

In addition, the pricing models can be affected by the market of rights exploitation (multi-channel pricing) and inspired by customer relationship (relationship pricing).

\section{Notes}

1 Eliashberg \& Shugan 1997; Basuroy, Chatterjee \& Ravid 2003; Doshi \& Krauss 2010; Foutz \& Jank 2010.

2 The theoretical framework does not take into account the phenomenon of piracy, which impacts negatively on net revenues potentially arising from the success of the product.

3 Costabile, 1992; Zeithaml, 1988.

4 Jacoby \& Kaplan (1972).

5 Kaplan, Zybillo \& Jacoby (1974).

6 For more details on output and volume deals, see chapter 7.

7 Stoetzel 1954; Adam 1958; Gabor \& Granger 1961, 1965; Monroe 1971.

8 Valdani (1986).

9 Porter (1983).

(c) (i) Except where otherwise noted, this work is licensed under a copy of this license, visit http://creativecommons.org/licenses/by/3.0/ 